\title{
12-month follow-up of an exploratory 'brief intervention' for high-frequency cannabis users among Canadian university students
}

\author{
Benedikt Fischer ${ }^{1,2^{*}}$, Wayne Jones ${ }^{1}$, Paul Shuper ${ }^{2,3}$ and Jürgen Rehm²,3
}

\begin{abstract}
Background: One in three young people use cannabis in Canada. Cannabis use can be associated with a variety of health problems which occur primarily among intensive/frequent users. Availability and effectiveness of conventional treatment for cannabis use is limited. While Brief Interventions (Bls) have been shown to result in short-term reductions of cannabis use risks or problems, few studies have assessed their longer-term effects. The present study examined 12-month follow-up outcomes for Bls in a cohort of young Canadian high-frequency cannabis users where select short-term effects (3 months) had previously been assessed and demonstrated.
\end{abstract}

Findings: $N=134$ frequent cannabis users were recruited from among university students in Toronto, randomized to either an oral or a written cannabis Bl, or corresponding health controls, and assessed in-person at baseline, 3-months, and 12-months. $\mathrm{N}=72(54 \%)$ of the original sample were retained for follow-up analyses at 12-months where reductions in 'deep inhalation/breathholding' $(Q=13.1 ; p<.05)$ and 'driving after cannabis use' $(Q=9.3 ; p<.05)$ were observed in the experimental groups. Reductions for these indicators had been shown at 3-months in the experimental groups; these reductions were maintained over the year. Other indicators assessed remained overall stable in both experimental and control groups.

Conclusions: The results confirm findings from select other studies indicating the potential for longer-term and sustained risk reduction effects of Bls for cannabis use. While further research is needed on the long-term effects of Bls, these may be a valuable - and efficient - intervention tool in a public health approach to high-risk cannabis use.

Keywords: Cannabis use, Frequent use, Young adults, Brief interventions, Prevention, Canada

\section{Background}

Cannabis use is prevalent in Canada; about one in ten adults are current users [1,2]. Use is disproportionately prevalent among young people (e.g., 15 - 24 years of age) including secondary and post-secondary students, where some $25 \%$ - $36 \%$ are current cannabis users [1,3]. A variety of health risks - including cognitive and psychomotor impairment, bronchial or pulmonary problems, mental health and dependence, injuries - are associated with cannabis use $[4,5]$. However, these problems disproportionately occur in a minority of users [6,7]. More specifically,

\footnotetext{
* Correspondence: bfischer@sfu.ca

${ }^{1}$ Centre for Applied Research in Mental Health and Addictions, Faculty of Health Sciences, Simon Fraser University, 2400, 515 West Hastings St., Vancouver, BC V6B 5K3, Canada

${ }^{2}$ Centre for Addiction and Mental Health, 33 Russell St., Toronto, ON M5S 2S1, Canada

Full list of author information is available at the end of the article
}

intensive (e.g., frequent/daily) users are at high risk for above problems and hence form a primary target group for interventions $[6,8,9]$.

Traditional treatment interventions are limited in availability and effectiveness. In this context, the utility of so-called 'Brief Interventions' (BIs) for reducing risk or problem outcomes from cannabis use has recently been examined. BIs are largely modelled after similar efforts in other substance use areas, mainly alcohol, where reductions in risk behaviors have been shown [10-12]. BIs for cannabis use usually consist of a small number of intervention units, delivered in varying formats, conveying information and/or motivational components towards reducing risk behaviors or problems $[13,14]$. BIs for cannabis use have been shown to achieve substantive short-term reductions in, for example, cannabis use frequency or problem indicators (e.g., 
dependence symptoms); however information on longer-term effects is limited $[15,16]$.

The objective of this present study was to assess the longer-term (i.e., 12-months) impact of a customized BI module for cannabis use on select risk outcome indicators, for which short-term (i.e., 3-months) impact was previously assessed and demonstrated, in frequent cannabis users among university students in a Canadian setting.

\section{Methods}

\section{Sample and recruitment}

Details of the study methods are provided in [17]. Briefly, participants were recruited from university student populations in Toronto by way of mass-advertising (i.e., posters on campuses) based on the following eligibility criteria: 18 - 28 years of age; full-time university enrolment; cannabis use > one year; cannabis use on at least 12 of the past 30 days. Study eligibility confirmation occurred by telephone, after which candidates were invited for the in-person and anonymous study appointment.

\section{Assessment and interventions}

Baseline assessments consisted of a short (25-30 minutes) interviewer-administered questionnaire after which participants were randomized to one of four BI groups: a cannabis (experimental) intervention delivered either orally $(\mathrm{C}-\mathrm{O})$ or in the form of written material $(\mathrm{C}-\mathrm{W})$, or a general health (control) intervention delivered orally $(\mathrm{H}-\mathrm{O})$ or via written material $(\mathrm{H}-\mathrm{W})$. The cannabis interventions consisted of short information elements on cannabis-related health risks, concrete suggestions for risk modification, and brief motivational components; the main aims of the BI were to inform users about key modifiable health risks related to use, and to suggest tangible ways to reduce these risks without principally focusing on or requiring abstinence. The control interventions were similarly structured and included general health information content (e.g., nutrition, stress, exercise). The oral BIs were delivered by a health psychologist in a 15 - 20 minutes long session; the written BIs were provided by a 10-page booklet with corresponding content. Follow-up assessments were conducted in-person at 3-months (FU3) and 12-months (FU12) following the BI, consisting of an abbreviated version of the baseline interview.

Participants provided informed consent for all study elements, and received small honoraria for baseline (\$25) and follow-up assessments (\$30 each). The study was approved by the investigators' institutional research ethics board.

\section{Measures and analyses}

Four measures (all 'in the past 30 days') collected at baseline and follow-up assessments were used to assess changes in key outcomes:
(1)Number of cannabis use days (continuous).

(2)Average number of cannabis use episodes per use day (continuous).

(3) Use of deep inhalation/breathholding techniques (yes/no).

(4)Driving a vehicle within 2 hours of use (yes/no).

The FU3 analysis found little difference between the oral and written BI modules, and thus the respective experimental and control groups were collapsed (i.e., $\mathrm{C}-\mathrm{O}+\mathrm{C}-\mathrm{W}$ and $\mathrm{H}-\mathrm{O}+\mathrm{H}-\mathrm{W})$ for analyses. On this basis, the two continuous measures were analysed by a 2 (intervention group [cannabis or health]) by 3 (measurement period [baseline, FU3, FU12]) ANOVA with repeated measures over period. To account for the correlated nature of the repeated measures the two categorical measures were examined using Cochran's $Q$ test (for changes over the 3 periods) and the more detailed comparisons between baseline and FU3, and FU3 and FU12 by McNemar's chi-square.

\section{Findings Study sample}

The baseline sample consisted of $n=134$ subjects. Of these, $n=113(84 \%)$ were reassessed at FU3, and $n=76$ (57 \%) were reassessed at FU12. Four subjects of the FU12 sample had not attended the FU3 assessment, meaning complete data for all three assessments resulted in an analysis (completer) sample of $\mathrm{n}=72(54 \%)$. Table 1 presents data on key socio-demographic characteristics (e.g., age, sex, years of university enrolment) and years of cannabis use for the baseline and completer samples and those lost to follow up (LTF). No differences were found for the above indicators between the completer and the LTF samples.

\section{Outcomes}

The repeated measures ANOVAs found no statistically significant main or interaction effects for 'cannabis use days' or the 'cannabis use episodes'. A change was observed for 'deep inhalation/breathholding' over the year for the experimental $(\mathrm{Q}=13.1 ; \mathrm{p}<.05)$ but not the control $(\mathrm{Q}=4.8$; ns) group. Similarly, a change was observed for 'driving after cannabis use' for the experimental $(\mathrm{Q}=9.3 ; \mathrm{p}<.05)$ but not the control $(\mathrm{Q}=0.9 ; \mathrm{ns})$ group. Changes observed occurred in the desired direction, i.e., reductions in risk behaviours. The most substantive changes for these variables had materialized between baseline and FU3; these effects were maintained at the FU12 assessments. Also, for the 'driving after cannabis use' variable, randomization appears to have resulted in a higher proportion in the experimental group at baseline reporting "Yes"; however this dropped to the level of the control group by FU3 and this effect was maintained over the year (see Table 2). 
Table 1 Key socio-demographic and cannabis use characteristics of baseline, completer and lost-to-follow-up samples, by intervention group

\begin{tabular}{|c|c|c|c|c|c|c|}
\hline \multirow[t]{2}{*}{ Sample } & \multirow{2}{*}{$\begin{array}{l}\text { Intervention } \\
\text { Group }\end{array}$} & \multicolumn{2}{|r|}{ Age } & \multirow{2}{*}{$\begin{array}{c}\text { Years of University } \\
\text { Mean (sd) }\end{array}$} & \multirow{2}{*}{$\begin{array}{c}\text { Years of Cannabis Use } \\
\text { Mean (sd) }\end{array}$} & \multirow{2}{*}{$\begin{array}{c}\text { Sex } \\
\text { Male }\end{array}$} \\
\hline & & $\mathbf{N}$ & Mean (sd) & & & \\
\hline \multirow[t]{3}{*}{ Baseline Sample } & All & 134 & $20.4(2.4)$ & $2.5(1.6)$ & $5.5(2.7)$ & $67.2 \%$ \\
\hline & Cannabis BI & 72 & $20.3(2.4)$ & $2.4(1.7)$ & $5.5(2.8)$ & $65.3 \%$ \\
\hline & Health $\mathrm{BI}$ & 62 & $20.6(2.5)$ & $2.6(1.5)$ & $5.6(2.6)$ & $69.4 \%$ \\
\hline \multirow[t]{3}{*}{ Completer (baseline, FU-3 and FU-12) Sample } & All & 72 & $20.3(2.2)$ & $2.5(1.4)$ & $5.7(2.8)$ & $68.1 \%$ \\
\hline & Cannabis $\mathrm{BI}$ & 40 & $20.1(2.1)$ & $2.3(1.5)$ & $5.9(3.0)$ & $67.5 \%$ \\
\hline & Health $\mathrm{Bl}$ & 32 & $20.6(2.3)$ & $2.7(1.3)$ & $5.5(2.6)$ & $68.8 \%$ \\
\hline \multirow[t]{3}{*}{ Lost-to-Follow-up Sample } & All & 62 & $20.6(2.7)$ & $2.5(1.7)$ & $5.3(2.6)$ & $66.1 \%$ \\
\hline & Cannabis $\mathrm{BI}$ & 32 & $20.5(2.7)$ & $2.6(1.8)$ & $5.0(2.4)$ & $62.5 \%$ \\
\hline & Health BI & 30 & $20.6(2.7)$ & $2.5(1.6)$ & $5.7(2.7)$ & $70.0 \%$ \\
\hline
\end{tabular}

No significant differences were detected for the above outcome variables at baseline between the experimental and control samples or between the completer and LTF samples.

\section{Discussion}

Our results suggest that reductions in two of four key risk outcome indicators following a BI delivered to highfrequency young cannabis users observed at FU3 (i.e., deep inhalation/breathholding and driving after cannabis use) were maintained at FU12. These results are, in principle, consistent with findings from the (few) other studies on longer term effects of BIs, suggesting that reductions in specific risk behaviors from cannabis BIs may be sustained beyond short-term periods. For example, Dennis et al. [18] found substantial increases in the number of abstinence days following several BIs for adolescent cannabis use maintained after one year; Stephens et al. [16] and Babor et al. [19] found post-BI reductions in cannabis use days and problem symptoms maintained for at least one year. Notably, our study did not see changes in cannabis use frequency or intensity itself, as witnessed by the above studies, but reductions were limited to the (rather specific) risk behavior variables. It needs further investigation to which extent this may be a function of the specific BI content applied, or possibly related to participants' dispositions that frequent cannabis use itself is not a behavior worthy of change.

While relevant impacts from BIs appear to materialize immediately following the interventions, the present longer-term outcomes may be viewed as an indication of the stability of such effects. On this basis, our results add to the growing evidence that BIs may be a potentially effective - and efficient - tool in decreasing key cannabis related risk behaviours relevant for individual and public health $[10,12,20]$. Specifically, deep inhalation/breathholding may increase the risk for pulmonary/bronchial problems, and driving after cannabis use is likely to result in impaired driving, associated with elevated risk for motor vehicle accident involvement and/or injury [4,9,21,22]. While the demonstrated reductions are limited to select indicators, and do not eliminate the specified risk

Table 2 Key study outcomes among completer sample, by intervention group, at baseline, 3-month follow-up (FU3) and 12-month follow-up (FU12)

\begin{tabular}{|c|c|c|c|c|c|}
\hline \multirow[t]{2}{*}{ Measure } & \multirow[t]{2}{*}{ Group } & \multirow[t]{2}{*}{$\mathbf{N}$} & \multicolumn{3}{|c|}{ Mean $(95 \% \mathrm{Cl})$} \\
\hline & & & Baseline & FU 3 & FU 12 \\
\hline \multirow[t]{2}{*}{ Number of days cannabis used } & Cannabis & 40 & $24.0(22.2-25.8)$ & $23.1(20.7-25.5)$ & $22.3(19.8-24.8)$ \\
\hline & Health & 32 & $23.9(21.8-26.0)$ & $23.1(20.6-25.5)$ & $22.1(18.9-25.3)$ \\
\hline \multirow[t]{4}{*}{ Number of cannabis use episodes/day } & Cannabis & 40 & $2.3(1.7-2.9)$ & $2.4(1.8-3.0)$ & $2.6(1.6-3.7)$ \\
\hline & Health & 32 & $2.0(1.7-2.3)$ & $2.4(1.5-3.4)$ & $2.2(1.7-2.6)$ \\
\hline & & & \multicolumn{3}{|c|}{ Proportion Responding YES } \\
\hline & & $\mathbf{N}$ & Baseline & FU 3 & FU 12 \\
\hline \multirow[t]{2}{*}{ Deep inhalation/ breathholding } & Cannabis* & 40 & $78 \%$ & $52 \%$ & $57 \%$ \\
\hline & Health & 32 & $81 \%$ & $78 \%$ & $68 \%$ \\
\hline \multirow[t]{2}{*}{ Driving after cannabis use } & Cannabis* & 40 & $44 \%$ & $31 \%$ & $24 \%$ \\
\hline & Health & 32 & $30 \%$ & $27 \%$ & $24 \%$ \\
\hline
\end{tabular}

* Significant change over periods $(p<.05)$. 
behaviors, conventional - and more resource-intensive treatment interventions do not appear to result in substantially more efficacious impacts $[10,12]$.

The sustained impact and intervention utility of BIs beyond just 'strawfire' effects may further be amplified - or extended to other behaviors - by way of implementing targeted 'booster' interventions, e.g., by way of follow-up calls, text messages, etc. $[18,23]$. Given their relative ease and flexibility in delivery, BIs can relatively easily be offered to high-risk groups in their natural environments or settings (e.g., universities) $[20,24,25]$

The results of the present study should be further tested in larger-scale studies examining different BI content and delivery method options with sufficient power and longerterm follow-ups, as well as ideally relying on an intent-totreat (rather than a completers_) analysis approach. Key limitations of the present study include its small sample size, reducing the sensitivity of our methods to detect potential effects. Specifically, the health controls seemed to indicate trends towards reductions in the risk factors under discussion that may have evolved to significance given more analytical power. In addition, there may have been un-measured extrinsic factors over the study period influencing participants' risk behaviors that could not be accounted for in the analysis. The study had a relatively substantial loss to follow up - largely due to high mobility in student cohorts - which could lead to selection biases, although we found no relevant differences between the analysis and LTF samples. The study relied primarily on self-reported data, the validity of which can be confounded (e.g., social desirability effects). The results of the study may not be generalizable to other cannabis user populations.

Overall, our study suggests the potential utility of BIs as an intervention tool in Canada where cannabis use is prevalent among young people, and BIs have largely been ignored in the substance use arena to date. In the context of increasing advocacy for public health oriented cannabis use policy in Canada, BIs may further be developed and utilized as a valuable intervention tool, primarily for secondary prevention purposes, for key risk populations $[4,20]$. At this point, the vast majority of intervention resources for cannabis use control in Canada are expended for criminalization (e.g., arrests of users); in addition, large-scale abstinence education or promotion campaigns are implemented with questionable impact. A small proportion of the resources used for the aforementioned programs would allow broad-based BI programs to be implemented for high-risk cannabis users in settings (e.g., universities, colleges) where such populations are disproportionately present and offer themselves well for such measures, as has been shown for other public health oriented intervention campaigns (e.g., sexual health education or nutritional education, etc.). In addition, other key stakeholders - e.g., non-governmental public health associations - could become involved in offering such BI programming.

\section{Competing interests}

The authors declare that they have no competing interests.

\section{Authors' contribution}

BF overall led the study. BF, JR and PS designed the study protocol. WJ, BF, PS and JR designed the analysis plan; WJ conducted the data analysis. All authors contributed to interpretation of the data, and to drafting and revising the present manuscript.

\section{Role of funding sources}

The authors acknowledge funding support from the Canadian Institutes of Health Research (CIHR), specifically Catalyst Grant \#211803, for this study. Drs. Fischer, Rehm and Shuper also acknowledge funding support from the Ontario Ministry of Health and Long-Term Care (MOHLTC). Dr. Fischer furthermore acknowledges salary support from a CIHR/PHAC Chair in Applied Public Health.

\section{Acknowledgements}

The authors acknowledge the work of Meghan Dawe and Fraser McGuire in participant assessments, and the assistance of Christina Myrick and Katherine Rudzinski in the preparation of this manuscript.

\section{Author details}

${ }^{1}$ Centre for Applied Research in Mental Health and Addictions, Faculty of Health Sciences, Simon Fraser University, 2400, 515 West Hastings St., Vancouver, BC V6B 5K3, Canada. ${ }^{2}$ Centre for Addiction and Mental Health, 33 Russell St., Toronto, ON M5S 2S1, Canada. ${ }^{3}$ Dalla Lana School of Public Health, University of Toronto, 155 College St., Toronto, ON M5T 3M7, Canada.

Received: 2 February 2012 Accepted: 11 April 2012

Published: 26 April 2012

\section{References}

1. Health Canada: Canadian Alcohol and Drug Use Monitoring Survey (CADUMS): Summary Results for 2010. 2011. Ottawa, ON: Health Canada; 2012:1-11.

2. United Nations Office on Drugs and Crime (UNODC): World Drug Report 2011. E.11.XI.10, Division for Policy Analysis and Public Affairs. Vienna Austria: United Nations Office on Drug and Crime (UNODC); 2011

3. Paglia-Boak A, Adlaf EM, Mann RE: Detailed OSDUHS Findings - Drug Use Among Ontario Students 1977-2011. CAMH Research Document Series. 32. 2011; 2012, 1-11

4. Room R, Fischer B, Hall W, Lenton S, Reuter P: Cannabis policy: moving beyond stalemate. New York, NY: Oxford University Press; 2010.

5. Hall W: The adverse health effects of cannabis use: What are they, and what are their implications for policy? Int J Drug Policy 2009, 20:458-466.

6. Hall W, Pacula RL: Cannabis Use and dependence: public health and public policy. Melbourne: Cambridge University Press; 2004.

7. Fischer B, Rehm J, Irving H, lalomiteanu A, Fallu J-S, Patra J: Typologies of cannabis users and associated characteristics relevant for public health: a latent class analysis of data from a nationally representative Canadian adult survey. Int J Meth Psychiatric Res 2010, 19:110-124.

8. Moore THM, Zammit S, Lingford-Hughes A, Barnes TRE, Jones PB, Burke M, et al: Cannabis use and risk of psychotic or affective mental health outcomes: a systematic review. Lancet 2007, 370:319-328.

9. Fischer B, Jefferies V, Hall W, Room R, Goldner E, Rehm J: Lower Risk Cannabis Use Guidelines for Canada (LRCUG): a narrative review of evidence and recommendations. Can J Public Health 2011, 102:324-327.

10. Copeland J, Swift W: Cannabis use disorder: epidemiology and management. Int Rev Psychiatry 2009, 21:96-103.

11. Rush B, Urbanoski K: Estimating the demand for treatment for cannabisrelated problems in Canada. Int J Mental Health Addiction 2007, 5:181-186.

12. McRae A, Budney A, Brady K: Treatment of marijuana dependence: a review of the literature. J Subst Abuse Treat 2003, 24:369-376.

13. Babor TF, McRee BG, Kassebaum PA, Grimaldi PL, Ahmed K, Bray J: Screening, Brief Intervention, and Referral to Treatment (SBIRT): toward a public health approach to the management of substance abuse. Subst Abus 2007, 28:7-30. 
14. Madras B, Compton W, Avula D, Stegbauer T, Stein J, Clark H: Screening, brief interventions, referral to treatment (SBIRT) for illicit drug and alcohol use at multiple healthcare sites: Comparison at intake and 6 months later. Drug Alcohol Depend 2009, 99:280-295.

15. Martin G, Copeland J: The adolescent cannabis check-up: randomized trial of a brief intervention for young cannabis users. J Subst Abuse Treat 2008, 34:407-414.

16. Stephens R, Roffman R, Curtis L: Comparisons of extended versus brief treatments for marijuana use. J Consult Clin Psychol 2000, 68:898-908.

17. Fischer B, Dawe M, McGuire F, Shuper P, Capler R, Bilsker D et al:. Feasibility and Impact of Brief Interventions for Frequent Cannabis Users in Canada. J Subst Abuse Treat (in press).

18. Dennis M, Godley S, Diamond G, Tims FM, Babor T, Donaldson J, et al: The Cannabis Youth Treatment (CYT) Study: Main findings from two randomized trials. J Subst Abuse Treat 2004, 27:197-213.

19. Babor T: Brief treatments for cannabis dependence: findings from a randomized multisite trial. J Consult Clin Psychol 2004, 72:455-466.

20. Fischer B, Rehm J, Hall W: Cannabis use in Canada - The need for a public health approach. Can J Public Health 2009, 100:101-103.

21. Ramaekers JG, Bergaus $\mathrm{G}$, van Laar M, Drummer $\mathrm{OH}$ : Dose related risk of motor vehicle crashes after cannabis use. Drug Alcohol Depend 2004, 73:109-119.

22. Hall W, Fischer $B$, Simon $L$, Reuter $P$, Room R: Making space for cannabis policy experiments. Addiction 2011, 106:1192-1193.

23. McKay JR: Is there a case for extended interventions for alcohol and drug use disorders? Addiction 2005, 100:1594-1610.

24. Leslie E: University campus settings and the promotion of physical activity in young adults: lessons from research in Australia and the USA. Heal Educ 2001, 101:116-125.

25. Werch CE, Carlson JM, Pappas DM, Edgemon P, Diclemente CC: Effects of a brief alcohol preventive intervention for youth attending school sports physical examinations. Subst Use Misuse 2000, 35:421-432.

doi:10.1186/1747-597X-7-15

Cite this article as: Fischer et al:: 12-month follow-up of an exploratory 'brief intervention' for high-frequency cannabis users among Canadian university students. Substance Abuse Treatment, Prevention, and Policy 2012 7:15.

\section{Submit your next manuscript to BioMed Central} and take full advantage of:

- Convenient online submission

- Thorough peer review

- No space constraints or color figure charges

- Immediate publication on acceptance

- Inclusion in PubMed, CAS, Scopus and Google Scholar

- Research which is freely available for redistribution

Submit your manuscript at 